ACCEPTED MANUSCRIPT

\title{
Corrigendum: Spider silk reinforced by graphene or carbon nanotubes (2017 2D Mater. 4 031013)
}

To cite this article before publication: Emiliano Lepore et al 2018 2D Mater. in press https://doi.org/10.1088/2053-1583/aad5fd

\section{Manuscript version: Accepted Manuscript}

Accepted Manuscript is "the version of the article accepted for publication including all changes made as a result of the peer review process, and which may also include the addition to the article by IOP Publishing of a header, an article ID, a cover sheet and/or an 'Accepted

Manuscript' watermark, but excluding any other editing, typesetting or other changes made by IOP Publishing and/or its licensors"

This Accepted Manuscript is @ 2018 IOP Publishing Ltd.

During the embargo period (the 12 month period from the publication of the Version of Record of this article), the Accepted Manuscript is fully protected by copyright and cannot be reused or reposted elsewhere.

As the Version of Record of this article is going to be / has been published on a subscription basis, this Accepted Manuscript is available for reuse under a CC BY-NC-ND 3.0 licence after the 12 month embargo period.

After the embargo period, everyone is permitted to use copy and redistribute this article for non-commercial purposes only, provided that they adhere to all the terms of the licence https://creativecommons.org/licences/by-nc-nd/3.0

Although reasonable endeavours have been taken to obtain all necessary permissions from third parties to include their copyrighted content within this article, their full citation and copyright line may not be present in this Accepted Manuscript version. Before using any content from this article, please refer to the Version of Record on IOPscience once published for full citation and copyright details, as permissions will likely be required. All third party content is fully copyright protected, unless specifically stated otherwise in the figure caption in the Version of Record.

View the article online for updates and enhancements. 


\section{Corrigendum: Spider silk reinforced by graphene or carbon nanotubes (2017 2D Mater. 4 031013)}

Emiliano Lepore ${ }^{1}$, Federico Bosia ${ }^{2}$, Francesco Bonaccorso ${ }^{3,4}$, Matteo Bruna ${ }^{3}$, Simone Taioli ${ }^{5,6}$, Giovanni Garberoglio ${ }^{5}$, Andrea. C. Ferrari ${ }^{3}$, Nicola Maria Pugno ${ }^{1,7,8^{*}}$

1 Laboratory of Bio-inspired \& Graphene Nanomechanics, Department of Civil, Environmental and Mechanical Engineering, University of Trento, Via Mesiano 77, 38123 Trento, Italy. 2 Department of Physics and "Nanostructured Interfaces and Surfaces" Centre, Università di Torino, Via P. Giuria 1, 10125, Torino, Italy. ${ }_{3}$ Cambridge Graphene Centre, University of Cambridge, $9 \mathrm{JJ}$ Thomson Avenue, Cambridge, CB3 OFA, UK 4 Istituto Italiano di Tecnologia, Graphene Labs, Via Morego 30, 16163 Genova, Italy. ${ }_{5}$ European Centre for Theoretical Studies in Nuclear Physics and Related Areas, Bruno Kessler Foundation \& Trento Institute for Fundamental Physics and Applications, Trento, Italy. ${ }_{6}$ Faculty of Mathematics and Physics, Charles University, Prague, Czech Republic. ${ }_{7}$ School of Engineering and Materials Science, Queen Mary University, Mile End Road, London E1 $4 N S, U K$. ${ }_{8}$ Ket Lab, Edoardo Amaldi Foundation, Italian Space Agency, Via del Politecnico snc, 00133 Rome, Italy.

*Corresponding author: nicola.pugno@unitn.it

In the Discussion at page 6 the definition of MASP 1 was "mannose-associated serine protease 1 (MASP 1)" and has to be corrected with "major ampullate silk protein 1 (MASP 1)" 